\title{
Big Data on BHR: Innovative Approaches to Analysing the Business \& Human Rights Resource Centre Database - ERRATUM
}

\author{
Nicole JANZ, James ALLEN-ROBERTSON, Rajeshwari MAJUMDAR and \\ Shareen HERTEL \\ doi: 10.1017/bhj.2020.18, Published online by Cambridge University Press, \\ 30 September 2020
}

In the above-mentioned article Rajeshwari Majumdar's name was given as Rajeswari Majumdar in the author information footnotes of the first page.

This has since been rectified in the online PDF and HTML versions. Cambridge University Press apologise for this error.

\section{REFERENCE}

JANZ, N., ALLEN-ROBERTSON, J., MAJUMDAR, R., \& HERTEL, S. (2020). Big Data on BHR: Innovative Approaches to Analysing the Business and Human Rights Resource Centre Database. Business and Human Rights Journal, 1-7. doi:10.1017/bhj.2020.18 